\title{
Las Industrias culturales de los Nadies
}

\section{Nadies' cultural industries}

COMUNICACIÓN

\author{
Denise Koziura Trofa \\ Universidad Nacional de Quilmes, Argentina. \\ denisekoziura10@gmail.com
}

Recibido: abril del 2016

Aceptado: agosto del 2016

\section{Resumen}

En el siguiente trabajo se analizan los retos que enfrenta América Latina y el Caribe en relación al desarrollo de sus industrias culturales. Se revisa la situación actual de las políticas culturales de la región, y los desafíos para el futuro.

Palabras clave: Industrias culturales; América Latina y el Caribe; políticas culturales.

\begin{abstract}
In this paper the challenges that Latin America and the Caribbean face in relation to the development of their cultural industries are analyzed. The current situation of cultural policies in the region, and the challenges for the future are reviewed.

Keywords: cultural industries; Latin America and the Caribe; cultural policies.

En 1989 Eduardo Galeano escribía en "El libro de los abrazos" sobre los nadies que querían salir de pobres, "Los nadies: los hijos de nadie, los dueños de nada. Los nadies: los ningunos, los ninguneados, corriendo la liebre, muriendo la vida, jodidos, rejodidos: Que no son, aunque sean. Que no hablan idiomas sino dialectos. Que no profesan religiones, sino supersticiones. Que no hacen arte, sino artesanía. Que no practican cultura, sino folklore" (Galeano, 2006, p. 59). Considero que vale la pena reparar en este poema, en lo que nos concierne como bien cultural, antes de empezar a preguntarnos cuáles son los retos que enfrentamos en América Latina y el Caribe, en relación con el desarrollo de las industrias culturales. Se busca reflexionar al respecto a lo largo de este escrito.
\end{abstract}


Como se dejó planteado en el texto "Industrias culturales, creatividad y desarrollo", según el Instituto de estadísticas de la UNESCO (2005), en el 2002 se estimaba que el aporte al total mundial de bienes y servicios culturales de América Latina y el Caribe era tan solo de un 3\% (Rey, 2009, p. 71). Al mismo tiempo, durante ese año, las exportaciones de bienes culturales en la región fueron de 1.633,5 millones de dólares, mientras que las importaciones fueron de 2.291,6 millones de dólares (Rey, 200, p. 73). Datos más actualizados, presentes en el Informe Economía Creativa 2013, han brindado un panorama muy similar: "Todos los países de la región están experimentando un déficit considerable en su balanza de pagos con respecto a los bienes y servicios culturales" (PNUD, UNESCO, 2014, p. 79).

Del mismo modo, aunque existe una rica interacción de bienes y servicios culturales latinoamericanos a modo interregional "En los catálogos la oferta y los consumos tienen un peso significativo los productos culturales locales"-, en el 2009 "el 83\% de las exportaciones de bienes culturales hacia América Latina e(ra) de los Estados Unidos" (Rey, 2009, p. 77-78).

Al respecto, el Informe sobre la Economía Creativa 2013 planteó que "la predominancia de los países del Norte global presenta un desafío de enormes proporciones para cualquier nuevo integrante, especialmente del Sur global" (PNUD, UNESCO, 2014, p. 26) y esto se vinculaba con que las corporaciones transnacionales dominantes, en general aquellas relacionadas con la distribución, se concentraban en el Norte global (PNUD, UNESCO, 2014, p. 30). Así se establecía que:

"Los países del Sur global deben competir con condiciones de un mercado mundial altamente asimétrico y sistemas de derechos de propiedad intelectual que aún funcionan en beneficio de los productores de la economía creativa y los exportadores de los países del Norte global' (PNUD, UNESCO, 2014, pp. 36-37).

Esto se refería a un tipo de industria cuyas exportaciones a nivel mundial alcanzaron un valor de 646 mil millones de dólares durante el 2011 (Buitrago Restrepo, Duque Márquez, 2013, p. 18).

Esa realidad, aunque adversa, no podía ser una excusa para rendirnos ante las circunstancias, "la historia está repleta de ejemplos de cómo (un) nuevo material, productos o expresiones de diversos sitios han entrado en el espacio de flujos mundiales" (PNUD, UNESCO, 2014, p. 84) como sucedió con el Tango o el Reggae, en la industria de la música.

\section{Políticas culturales para la región: Producción, Circulación y Consumo}


Dado este panorama, podemos dividir los principales retos de la región en relación al desarrollo de las industrias culturales en tres frentes: producción, circulación y consumo. Los tres, sin embargo, confluyen en un mismo punto: las políticas culturales.

América Latina y el Caribe, así como otros países en desarrollo, han poseído carencias en relación a las regulaciones de las industrias culturales. Uno de los retos que debemos enfrentar es tratar de dilucidar cuál es papel del mercado en esas políticas y cuál es el papel del Estado en las mismas.

Latinoamérica y el Caribe poseen políticas culturales débiles a nivel nacional, áreas culturales acaparadas por grandes empresas monopólicas nacionales y transnacionales, "ausencia de promoción de la creatividad local y de las productoras independientes o la asimilación de dicha creatividad a exigencias comerciales y de los mercados" (Rey, 2009, p. 78). Ante la presencia de las grandes transnacionales, la región requiere del establecimiento de políticas culturales que breguen por la protección de las industrias culturales regionales. Pero, idealmente, estas medidas, más que tener carácter subsidiario, deberían ayudarlas a volverse competitivas. De no ser así, y depender por completo del erario público -mediante la pauta publicitaria o el subsidio directo-, estas industrias corren el riesgo de ser víctimas del clientelismo político y de los caprichos de los gobiernos de turno.

Asimismo, las industrias culturales, presas del libre mercado, deben luchar contra la extranjerización. La concentración de la propiedad es uno de los problemas propios de estas industrias -dados sus altos costos fijos y los bajos costos variables, y la dinámica económica-. Las empresas de medios crecen o desaparecen, o en otras palabras, son absorbidas por un grupo más grande. "Como la economía creativa es de alto riesgo y difícil gestión, a las grandes organizaciones que puedan extender el riesgo a una cartera de productos y servicios les será más fácil prosperar" (PNUD, UNESCO, 2014, p. 26). Por eso son necesarias normas que regulen este tipo de empresas, recordando que estas industrias aportan "un valor añadido a los contenidos, al tiempo que construyen y difunden valores culturales de interés individual y colectivo. ( $\mathrm{Y}$ ) son por ello esenciales para promover la diversidad cultural, así como para democratizar el acceso a la cultura" (Rey, 2009, p. 69).

La implementación de políticas débiles -y en algunos casos inexistentes- se explica, en parte, debido a que "en los países en desarrollo, la cultura compite desigualmente con otras áreas de inversión del Estado y sobre todo del conjunto de sus necesidades, por lo general muy apremiantes y básicas. Esta situación se agrava por una comprensión de la cultura como conservación, bellas artes y gasto" (Rey, 2009, p. 60). Por lo tanto, uno de los retos que poseemos radica en cambiar la concepción de "cultura" que tenemos como 
sociedad, y comenzar a percibir las potencialidades que encierra la creatividad como estímulo para el desarrollo de los países.

Las industrias creativas (...) no solamente permiten a los países contar sus propias historias y proyectar sus propias identidades culturales a ellos mismos y al mundo, sino que pueden mejorar a estos países con una fuente de crecimiento económico, creación de empleos y obtener mayor participación en la economía global (PNUD, UNESCO, 2014, p. 38).

La relevancia que le demos a la cultura no solo se verá reflejada en las políticas culturales a nivel nacional, sino que traerá consecuencias en lo que respecta a las disposiciones de la Organización Mundial de Comercio (OMC) y a los tratados de libre comercio - "algunas de las disposiciones culturales más importantes se juegan hoy en los tratados de libre comercio" (Rey, 2011, p. 85). Históricamente, durante sus rondas, Estados Unidos -país hegemónico en la materia- puja por considerar a los productos culturales como otras mercancías "cuya circulación debe tener el mínimo de barreras comerciales y por supuesto regulativas" (Rey, 2009, p. 66), y los representantes de nuestra región en ocasiones no están a la altura de las circunstancias. Si los representantes de América Latina y el Caribe en la OMC no están capacitados en relación a las industrias culturales, se corre el riesgo de que consientan el enfoque de Estados Unidos, y pierdan de vista que los bienes y servicios culturales "no se agotan en su condición de mercancías, sino que comportan modos de vida, axiologías y sistemas de conocimiento. Son muy importantes en la configuración de identidades, la cohesión social y la convivencia" (Rey, 2009, p. 69). Por lo tanto, uno de los grandes retos que enfrenta nuestra región es el de formar profesionales en industrias culturales, aptos para participar tanto en estos debates, como en otros ámbitos conformadores de políticas públicas relativas a dichas industrias.

El problema de la producción y circulación de los bienes y servicios culturales de América Latina y el Caribe -aún teniendo en cuenta que algunos de los países de la región, como es el caso Argentina, Brasil, Chile, Colombia y Cuba, tienen una economía creativa desarrollada en comparación a los demás países de dicha región (PNUD, UNESCO, 2014, p. 79)-, está relacionado con la condición asimétrica que existe entre las industrias locales y la de los países más poderosos. Sin embargo, el desarrollo local se alcanza en la promoción de la distribución de bienes y servicios a nivel interregional mediante la creación de alianzas con fines culturales entre los países de la región. De esta manera, se alienta la creatividad en la producción local, se evita la homogeneización -la imitación a las producciones de los países desarrollados como receta para el éxito-, y se fomenta la creación de nuevos circuitos de distribución.

Dicho esto, un último reto ha de hallarse en la promoción del consumo de los bienes y servicios culturales de la región. Esto será posible solo si primero erradicamos la idea de 
que "cultura es eso que hacen afuera", y ayudamos a construir el público consumidor de nuestros bienes culturales. Esta tarea no solo requiere de tácticas publicitarias, sino también de planes estratégicos que muchas veces se cruzan con lo educativo: si quiero aumentar el consumo de bienes y servicios culturales serán vitales, por ejemplo, los esfuerzos por luchar contra el analfabetismo digital en la región. "La formación de públicos repercute, a su vez, en la formación de la sensibilidad, el espíritu crítico y el reconocimiento de las diferencias, todas dimensiones básicas de la convivencia en paz" (Rey, 2009, p. 135). Volviendo sobre la cita de Galeano al comienzo de este ensayo, si bien debemos ponernos como objetivo dejar de ser vistos como nadies, el reto más grande al que nos enfrentamos hoy, es dejar de creerlo nosotros mismos.

\section{Referencias bibliográficas}

Buitrago Restrepo, F. y Duque Márquez, I. (2013). La Economía Naranja: Una oportunidad infinita. Bogotá: Banco Interamericano de Desarrollo.

Galeano, E. (2006). El libro de los abrazos. Buenos Aires: Siglo XXI.

Rey, G. (2011). Las políticas comunicativas de nueva generación y sus efectos. Entre el pensamiento único y las posibilidades de diversidad. En Campos Freire, F.; El nuevo escenario mediático. Zamora: Editorial Comunicación Social S.C.

Rey, G. (2009). Industrias Culturales, creatividad y Desarrollo. Madrid: Agencia española de Cooperación Internacional para el Desarrollo.

PNUD; UNESCO (2014). "Informe sobre la Economía Creativa 2013". México: Offset Santiago. Recuperado de: http://www.unesco.org/culture/pdf/creative-economy-report2013-es.pdf

PNUD; UNESCO; (2010) Economía creativa. Informe 2010: Una opción factible de desarrollo. Concepción: Naciones Unidas. URL: http://www.unctad.org/creativeprogramme 